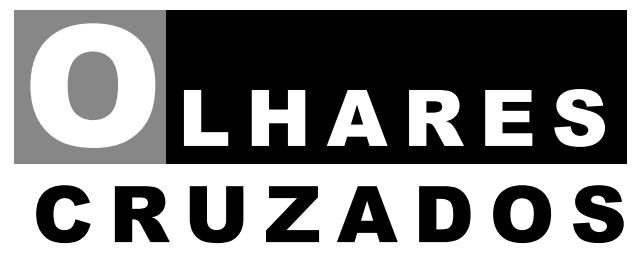





\section{Em briga de marido e mulher, o Poder Público mete a colher: mídia, mobilizações coletivas e estratégias de visibilização da violência doméstica em Portugal e no Brasil'}

Private husband-and-wife fights should be meddled by the Public Powers: media, collective mobilization and strategies for visibility of domestic violence in Portugal and Brazil

\section{Edilson Márcio Almeida da Silva}

Professor do Departamento de Antropologia e do Programa de Pós-Graduação em Antropologia da Universidade Federal Fluminense, Pesquisador do Núcleo Fluminense de Estudos e Pesquisas da Universidade Federal Fluminense (NUFEP/UFF) e do Instituto de Estudos Comparados em Administração Institucional de Conflitos (INCT/InEAC), Doutor em Antropologia pelo Programa de Pós-Graduação em Antropologia da Universidade Federal Fluminense (PPGA/UFF).

\section{Resumo:}

Dadas as transformações relativas a produção, armazenamento e fluxo de informações no mundo contemporâneo, a visibilidade dos fenômenos sociais encontra-se, não raro, relacionada ao modo como estes são tratados pela mídia. Por consequência, considerada a especificidade de sua participação na definição do que é socialmente relevante, a mídia contribui de forma decisiva para o agendamento das políticas públicas nas mais diversas áreas, inclusive na de segurança. A fim de discutir a capacidade de "agendamento" dos veículos de comunicação sobre os formuladores de políticas públicas, tomar-se-á como exemplo o processo de criminalização da violência doméstica

Este paper é resultado do estágio pós-doutoral realizado, entre os anos de 2011 e 2012, na Universidade Nova de Lisboa, pelo Programa CAPES/FCT - Edital CGCI no 0010/2009, no âmbito do Projeto "Modernidade e Justiça: controvérsias, causas públicas e participação política numa perspectiva comparada Portugal/ Brasil", coordenado pelos profs. Roberto Kant de Lima e José Manuel Resende. Uma versão preliminar foi apresentada no GT "Políticas Públicas en Seguridad, Justicia y Derechos Humanos: Etnografías de las Burocracias Estatales y de los Procesos de Demanda de Derechos", que compôs a programação da XI Reunión de Antropología del Mercosur ("Diálogos, prácticas y visiones antropológicas desde el sur”), realizada na cidade de Montevidéu (Uruguai), entre os dias 30 de novembro e 4 de dezembro de 2015. O GT foi coordenado pelas Professoras María Victoria Pita e Ana Paula Mendes de Miranda, contando, ainda, com os comentários da Professora Mariana Inés Godoy. A elas, os mais sinceros agradecimentos pelo aceite, comentários e críticas dirigidos ao trabalho. 
em Portugal, procurando assinalar a importância estratégica da mídia na sua visibilização e, por corolário, na sua construção como um dos principais problemas públicos do país. O objetivo geral do trabalho é, ainda que de forma sucinta, estabelecer uma perspectiva comparativa e contrastiva com o que, a esse respeito, se verifica no Brasil.

Palavras-chave: Mídia, Construção Social da Realidade, Violência Doméstica, Agendamento de Políticas Públicas.

\section{Abstract:}

Given the changes on the information production, storage and flow in the contemporary world, the visibility of social phenomena are often related to how they are addressed by the media. Therefore, given the specificity of its participation in defining what is socially relevant, the media has a critical role in the setting of the agenda of public policies in several areas, including the security one. Aiming to discuss the capacity of "setting the agenda" of the media vehicles on the public policy makers, this paper will take as an example the process of criminalization of domestic violence in Portugal, trying to point out the strategic relevance of the media in its visualization and, as corollary, in its construction as one of the major public problems of the country. Albeit briefly, the overall objective of this study is to establish a comparative and contrastive perspective with what is, in this regard, observed in Brazil.

Keywords: Media, Social Construction Of Reality, Domestic Violence, Setting Of The Agenda Of Public Policies.

\section{INTRODUÇÃO}

A mídia é atualmente um dos mais importantes agentes de construção social da realidade. Dadas as modernas transformações no intercâmbio das formas simbólicas, ela tem assumido relevância crescente, passando a se envolver de modo cada vez mais ativo na própria construção 
e reconstrução do mundo social. A esse respeito, como observa Thompson (2002, p. 106),

Ao levar as imagens e as informações para indivíduos situados nos mais distantes contextos, a mídia modela e influencia o curso dos acontecimentos, cria acontecimentos que poderiam não ter existido em sua ausência. Além do mais, os indivíduos envolvidos nestes acontecimentos podem estar bem conscientes do papel construtivo (ou destrutivo) da mídia [...]. Eles [os produtores e transmissores] sabem que, controlando o fluxo de imagens e de informações, a mídia desempenha um importantíssimo papel no controle do fluxo de acontecimentos.

Numa palavra, pode-se afirmar que os agentes midiáticos mobilizam os meios técnicos à sua disposição a fim de se comunicar com outros distantes, de tal sorte que, embora haja quem não lhes dê atenção e, portanto, lhes seja indiferente, "muitos indivíduos planejam suas atividades em parte baseados nas imagens e informações recebidas através da mídia” (THOMPSON, 2002, p. 107). Isso se deve, entre outras razões, ao fato de que, ao produzir e difundir informações sobre determinados acontecimentos, a mídia lhes empresta visibilidade, contribuindo, de modo decisivo, para a formação da opinião pública a seu respeito. Para tanto, são mobilizados recursos diversos, dentre os quais merece destaque a alta credibilidade pública de que os jornalistas são detentores no desempenho de suas funções.

No presente artigo, pretende-se mostrar, a partir da análise de um caso empírico, que os agentes midiáticos não são meros informantes do que se passa no mundo, mas também seus intérpretes, que, como tais, fazem escolhas, definem prioridades e produzem enquadramentos do real. Por meio do processo de produção das informações jornalísticas, tais agentes são capazes de produzir efeitos que reverberam, tanto direta quanto indiretamente, sobre aquilo a que, conforme mencionado, se convencionou chamar de construção social da realidade (BERGER e LUCKMANN, 2002).

Constituindo-se num dos principais agentes de produção e legitimação institucional de verdades do mundo contemporâneo, pode-se di- 
zer que, se a mídia não cria propriamente a realidade, ela constitui um instrumento fundamental para sua reprodução, já que atua de modo privilegiado na divulgação dos fatos tidos como socialmente relevantes (KANT DE LIMA; MISSE; MIRANDA, 2000). Dada a sua reconhecida credibilidade e o seu alcance, a interferência da mídia se faz notar nas mais diversas esferas da vida social, inclusive na área de segurança pública. Prova disso é que numa cidade brasileira de grande porte, como São Paulo, Belo Horizonte ou Rio de Janeiro, seria no mínimo implausível, por exemplo, o comandante de um batalhão da Polícia Militar definir a distribuição dos seus efetivos sem levar em conta o que foi publicado nos jornais do dia ou mesmo o que, na véspera, foi manchete dos principais jornais televisados.

Evidentemente, a interferência da mídia na área da segurança pública vai muito além disso. Não raro, a grande mídia participa, de diferentes modos, do agendamento das políticas públicas, sendo a sua capacidade de fazê-lo reconhecida tanto por seu público-alvo (que a ela pode recorrer com demandas as mais diversas) quanto pelos próprios agentes do Estado. Para produzir tal agendamento, os jornalistas devem ser capazes de não só noticiar como politizar determinados temas, fazendo com que, mais que meros problemas sociais, eles assumam a condição do que se convencionou chamar contemporaneamente de problemas públicos. O modo como isso se realiza é o tema do paper que se segue.

\section{A MÍDIA E A CRIMINALIZAÇÃO DA VIOLÊNCIA DOMÉSTICA EM PORTUGAL}

A fim de ilustrar a participação da mídia no agendamento das políticas públicas, tomar-se-á o processo de criminalização de um tipo específico de violência num contexto, sob muitos aspectos, distante e distinto do brasileiro: o português. O objetivo é estabelecer uma perspectiva comparativa e contrastiva com o que, a esse respeito, se verifica no Brasil. 


\section{0 contexto da violência doméstica em Portugal: dados oficiais versus casos noticiados}

A despeito das múltiplas diferenças existentes entre Brasil e Portugal, pode-se notar que, em ambos os países, as notícias sobre fenômenos "violentos" costumam ser relativamente frequentes, tanto nos veículos populares quanto nos noticiosos ${ }^{2}$. No que diz respeito mais especificamente à mídia portuguesa, é possível observar que um determinado tipo de ação criminosa tende a assumir posição de destaque nos noticiários. Trata-se da violência doméstica, classificada pelo jornal Diário de Notícias como "um dos maiores flagelos da sociedade atual" (DIÁRIO DE NOTÍCIAS $^{3}$, 2012, p. 19).

Embora não seja o propósito deste trabalho tratar do fenômeno em si, mas das representações midiáticas infundidas a seu respeito e, consequentemente, de sua politização, tomar-se-á como ponto de partida a definição de violência doméstica como a adoção de comportamentos de agressão, abuso de poder ou omissão nos quais uma pessoa inflige algum tipo de sofrimento a outra. Via de regra, esse tipo de violência ocorre entre sujeitos que têm ou tiveram uma relação de intimidade (cônjuges, companheiros, namorados etc.), familiar (ascendentes ou descendentes) ou de dependência. Ainda que as mulheres costumem ser as vítimas preferenciais, a violência doméstica não atinge só a elas, mas também crianças, pessoas idosas, deficientes, dependentes, dentre outros. Nesse sentido, uma vez que as ações violentas não partem única ou necessariamente do marido/companheiro, podem, também, as mulheres assumir, por vezes, o papel de agressoras.

\footnotetext{
Uma das distinções fundamentais entre os veículos populares e os noticiosos (também chamados de quality papers) é que, nestes, pretende-se "informar de forma objetiva e sem tentar provocar algum tipo de sensação ou envolvimento emocional dos leitores” (ALVES, 2001, p. 15). Evidentemente, essa taxionomia serve a fins meramente analíticos, posto que, ao fim e ao cabo, a propalada "objetividade jornalística" simplesmente inexiste. Mesmo porque "transformar um fato em notícia não é o mesmo que reproduzir singelamente o que ocorreu. Transformar um fato em notícia é também alterá-lo, dirigi-lo, mutilá-lo" (MARCONDES FILHO, 1986, p. 66).

3 Fundado em 1864, o Diário de Notícias é um dos principais jornais generalistas portugueses. Com circulação diária e nacional, costuma ocupar o primeiro lugar entre os jornais de referência, o que, no Brasil, equivaleria aos chamados quality papers.
} 
Com notável destaque em, praticamente, toda a mídia lusitana, as notícias sobre violência doméstica só costumam ser superadas, em recorrência, por aquelas que se referem à "violência" no sentido amplo e genérico, como no exemplo a seguir:

\section{VIOLÊNCIA}

O Alto Representante da ONU para as Civilizações, Jorge Sampaio, criticou a banalização da violência da última década e elogiou Lisboa como exemplo de harmonia religiosa. (Correio da Manhã ${ }^{4}$, edição de 5 de fevereiro de 2012, p. 32, Seção Política)

No exemplo apresentado, o jornal emprega o termo violência sem fazer referência a quaisquer cursos de ação ou mencionar o(s) responsável(is) por sua "banalização". A violência, no caso, é representada, a um só tempo, como resultado de ações sem sujeito e como um mal genérico difuso que, pelo menos supostamente, todos sabem do que se trata - algo bastante recorrente não só na imprensa portuguesa como na brasileira.

De acordo com diversos jornalistas e representantes de Organizações Não-Governamentais (ONGs) que lidam com a questão da violência doméstica em Portugal, tal destaque na mídia (ou entre os media, como dizem os patrícios) corresponde a um fenômeno ainda recente, posto que a mobilização em torno da temática só começou a obter visibilidade no ano de 2009, a partir de um episódio que representa, para muitos, um verdadeiro marco na luta pelos direitos das mulheres. Como ocorre todo ano, em 2009, o Ministério da Administração Interna - que tem, entre suas múltiplas atribuições, a execução das políticas de segurança pública - apresentava, numa cerimônia pública, o Relatório Anual de Segurança Interna (RASI), documento do governo que traça o panorama da criminalidade nas diferentes regiões de Portugal, tendo por base as ocorrências participadas às principais forças de segurança do país, quais sejam:

${ }_{4}$ Classificado como um jornal popular, o Correio da Manhã, fundado em 1979, é o atual líder de vendas entre os generalistas portugueses, com mais de $40 \%$ da quota de mercado dos jornais diários. 
- a Polícia de Segurança Pública (PSP);

- a Guarda Nacional Republicana (GNR); e

- a Polícia Judiciária (PJ) 5 .

Naquele contexto, o RASI contabilizava, para o ano de 2008, um total de dez casos de mulheres mortas por violência doméstica, em consequência das agressões sofridas por maridos, companheiros ou namorados. Oíndice, considerado muito aquém do verificado por agentes sociais envolvidos com a questão, surtiu reações as mais diversas. Uma delas foi que, em resposta à divulgação do RASI, a União de Mulheres Alternativa e Resposta (UMAR) ${ }^{6}$, das mais representativas e atuantes associações em prol da defesa dos direitos das mulheres em Portugal, apresentou ao Ministério da Administração Interna um relatório próprio, no qual não só contestava os dados oficiais, como exigia que tais crimes fossem analisados separadamente dos demais casos de homicídio.

Elaborado com base em informações veiculadas pela imprensa local, o documento apresentado pela UMAR mostrava que, na verdade, pelo menos, 41 mulheres (e não apenas dez, como indicava o relatório do governo) teriam sido assassinadas no país, durante o ano de 2008. Com base nisso, a associação defendeu a necessidade de se "individualizar" o crime de violência doméstica nas estatísticas oficiais sob o risco de, ao deixar de fazê-lo, não lhe conferir a devida importância e, ao mesmo tempo, deixar de reconhecer as suas especificidades. Um dos resultados diretos da mobilização e do debate públicos em torno da questão foi a criminalização da violência doméstica, cuja formalização se deu com a criação da Lei de 16 de setembro de 2009 (Lei nº 112/2009), por meio da qual se definiu um novo regime jurídico aplicável à prevenção da violência doméstica, assim como à proteção e à assistência das suas vítimas.

\footnotetext{
Formalmente, a Polícia de Segurança Pública (PSP) é a força de segurança responsável pelo policiamento fardado e ostensivo nas grandes áreas urbanas de Portugal, cabendo o policiamento das áreas rurais à Guarda Nacional Republicana (GNR). Já a Polícia Judiciária (PJ), que integra o Ministério da Justiça e atua sob orientação do Ministério Público, é a principal força de investigação criminal portuguesa.

6 Fundada em 12 de setembro de 1976, a União de Mulheres Alternativa e Resposta (UMAR) é uma organização não-governamental portuguesa de luta pelos direitos das mulheres. Em sua agenda estão temas como o direito à contracepção e ao aborto, a luta contra a violência doméstica e a paridade nos órgãos de decisão, dentre outros.
} 
No que diz respeito aos propósitos deste artigo, deve-se destacar a importância da divulgação das notícias sobre agressões sofridas por mulheres em território português ${ }^{7}$, posto que elas não só serviram de base empírica, como contribuíram de forma direta e significativa para que a sociedade civil questionasse os dados oficiais do Estado, levando ao advento da Lei no 112/2009.

Desde que foi criminalizada, a violência doméstica tornou-se um crime público em Portugal. Entre outras coisas, isso significa que não há necessidade de que a pessoa ofendida se queixe, cabendo ao Ministério Público acionar e promover o processo-crime ${ }^{8}$, independentemente de denúncia. Na prática, qualquer cidadão que tenha conhecimento do delito pode denunciá-lo (inclusive, anonimamente) a um órgão de polícia criminal, que deve registrar a queixa para, posteriormente, encaminhá-la ao Ministério Público. No contexto lusitano, o crime de violência doméstica é de denúncia obrigatória para as polícias, assim como para profissionais que dele tomem conhecimento no exercício de suas funções ou por causa delas. Trata-se de um crime único, posto que, para a sua caracterização, não se faz necessário que haja uma conduta reiterada, repetitiva ou habitual por parte do agressor. O crime de violência doméstica está previsto no artigo $152^{\circ}$ do Código Penal e o agressor pode cumprir pena de dois a oito anos. No caso de a agressão resultar em morte da vítima, o algoz pode ser condenado a até dez anos de prisão.

\section{A criminalização da violência doméstica no Brasil}

Também, no Brasil, a violência doméstica passou por um processo de criminalização ${ }^{9}$, que ocorreu anos antes de Portugal e culminou na criação da

\footnotetext{
Em Portugal, a exemplo do que ocorre em vários países (inclusive, no Brasil), quando se fala em violência doméstica o crime tem, majoritariamente, como vítimas mulheres, sobretudo as casadas. Os principais tipos de violência são: agressões físicas, verbais e sexuais.

8 Segundo o Dicionário Priberam da Língua Portuguesa, processo-crime é todo "processo judicial instaurado com base no pressuposto de ter sido cometido um ato criminal".

9 Ao afirmar-se que a criminalização da violência doméstica se efetivou, no Brasil, com a criação da Lei 11.340/06, não se pretende, de modo algum, negligenciar o fato de que a sua promulgação está ligada a um laborioso processo no qual teve importante lugar a instituição das Delegacias Especiais de Atendimento à Mulher, ainda década de 1980. Outrossim, não há como deixar de registrar aqui os agradecimentos à professora Lana Lage da Gama Lima por seus pertinentes comentários a esse respeito. Todavia, num sentido algo diverso do que sustenta a pesquisadora, pode-se argumentar que, de um ponto de vista racional-legal, talvez as DEAMs tenham cumprido mais um papel de criminação do conjunto de eventos
} 
Lei 11.340/06, sancionada em 7 de agosto de 2006. Elaborada com base num longo processo de discussões e audiências públicas, dos quais participaram múltiplos segmentos sociais, a Lei 11.340/06 tornou-se popularmente conhecida como Lei Maria da Penha, em homenagem a uma farmacêutica de mesmo nome, que ficou paraplégica após sofrer duas tentativas de homicídio pelo marido em sua própria residência (primeiramente, com arma de fogo e, depois, por eletrocussão e afogamento).

De acordo com o texto jurídico brasileiro, o agressor tanto pode ser preso em flagrante como preventivamente, desde que apresente riscos à integridade física ou psicológica da vítima. A Lei 11.340/06 prevê “pena de três meses a três anos de detenção para a violência familiar e doméstica contra a mulher, aumentada de $1 / 3$ se a vítima for portadora de necessidades especiais" (LIMA; SOUZA, 2010, p. 77). Todavia, diferentemente do que se observa no contexto português, mesmo decorridos alguns anos de sua implementação, "continua grande a resistência dos policiais, bem como dos operadores da justiça, à aplicação da nova lei, chegando à alegação de sua inconstitucionalidade" (LIMA; SOUZA, 2010, p. 77).

Sem sombra de dúvidas, os óbices à aplicação da Lei Maria da Penha têm a ver com fatores múltiplos, de ordem diversa. Dentre esses fatores, merece destaque uma certa tradição de se tratar os casos de violência doméstica como conflitos de proximidade, isto é, como problemas que devem ser resolvidos na esfera privada e não trazidos para a esfera pública (tal qual sugere o adágio que serviu de inspiração para o título deste trabalho: "em briga de marido e mulher, ninguém mete a colher"). No Brasil, por serem encarados como infrações de pequeno potencial ofensivo, os conflitos de proximidade, tais como desentendimentos, bate-bocas ou brigas envolvendo vizinhos, parentes, amigos e afins, costumam ter a sua importância minimizada em comparação com outros cursos de ação, tidos como mais violentos. Daí o recorrente pouco caso e a mencionada resistência à Lei 11.340/06.

que, ulteriormente, seriam enquadrados pela Lei Maria da Penha do que, de fato, de criminalização da violência doméstica. Para uma discussão acerca da distinção analítica entre os processos de criminação e criminalização, cf. MISSE, Michel. Sobre a acumulação social da violência no Rio de Janeiro. Civitas: Revista de Ciências Sociais, v. 8, n. 3, Porto Alegre, p. 371-385, 2008. 
Isso não quer dizer que, no Brasil, a violência doméstica seja um assunto considerado desimportante ou que a mídia não lhe confira alguma visibilidade. Prova disso é que a temática já foi abordada até mesmo em folhetins no horário nobre da principal emissora de TV do País, a Rede Globo de Televisão ${ }^{10}$. A visibilidade que a telenovela conferiu à questão decerto contribuiu para que casos de violência doméstica passassem a ser tratados como algo relevante, forjando, assim, uma nova sensibilidade que, ao menos formalmente, acabou por se refletir no plano jurídico nacional. Não obstante, apesar disso - e é esse, precisamente, um dos grandes dilemas da violência doméstica no Brasil -, ao contrário do que se passa em outros países, tal tipo de crime ainda não alcançou o estatuto de tema prioritário nem na mídia, nem na área de segurança pública, reservando-se tal destaque, no contexto brasileiro, ao crime organizado a partir do tráfico varejista de drogas ilícitas, a assim chamada criminalidade urbana violenta.

Exemplo do que ora se afirma pode ser apresentado a partir de um caso reconhecidamente pontual, mas bastante ilustrativo da visibilidade assimétrica alcançada no Brasil, por um lado, pelas representações acerca da violência doméstica e, por outro, pelas relativas à criminalidade urbana violenta. Pois bem, no ano de 2007 , foi firmado um contrato entre a Universidade Federal Fluminense - por meio do Núcleo Fluminense de Estudos e Pesquisas (NUFEP) - e a Prefeitura Municipal de São Gonçalo para a elaboração do Diagnóstico de Segurança Pública deste município da Metropolitana do estado do Rio de Janeiro ${ }^{11}$, situado a 20 quilômetros da capital e com uma população estimada em mais de um milhão de habitantes. Para a realização do Diagnóstico Municipal de Segurança

\footnotetext{
${ }_{10}$ Na telenovela Mulheres apaixonadas, de 2003, a professora Raquel, interpretada pela atriz Helena Ranaldi, costumava ser sistematicamente agredida pelo marido Marcos, vivido pelo ator Dan Stulbach, mas não tinha coragem de denunciá-lo à polícia. Entre outros atos de violência, Marcos costumava espancar a mulher com uma raquete de tênis, o que gerava fortes reações no público e promovia acalorados debates sobre o tema.

${ }_{11}$ O referido Diagnóstico de Segurança Pública foi elaborado com recursos da Prefeitura Municipal de São Gonçalo e da FINEP (Financiadora de Estudos e Projetos - Ministério da Ciência e Tecnologia) - Projeto Segurança Pública e Violência Urbana: a descentralização de formas institucionais de administração de conflitos (2006-2008).
} 
Pública de São Gonçalo foram utilizadas duas estratégias metodológicas distintas que, ao final da pesquisa, geraram alguns resultados aparentemente díspares, mas significativamente complementares.

Uma primeira etapa da pesquisa consistiu no levantamento dos dados quantitativos sobre tópicos relativos às características sociodemográficas do município, oferta de serviços de infraestrutura, ocupação de mão de obra, sistema educacional, sistema de saúde, violência, criminalidade e administração da justiça, entre outros. ${ }^{12}$ Já a segunda teve por base o emprego de técnicas qualitativas de pesquisa, tais como entrevistas, observação direta e grupos focais. Nesta etapa da pesquisa, além do acompanhamento sistemático do noticiário sobre a criminalidade e a segurança no município de São Gonçalo ${ }^{13}$, buscou-se ouvir representantes do poder público e da sociedade civil organizada. Outrossim, entre os diversos entrevistados constaram juízes e promotores, membros do legislativo municipal, secretários e demais gestores de políticas públicas da prefeitura, representantes de associações de moradores e de associações ligadas ao comércio, membros de conselhos comunitários, agentes da Polícia Militar, da Polícia Civil, da Polícia Rodoviária Federal e da Guarda Municipal, entre outros.

Um dado quantitativo que chamou bastante a atenção dos pesquisadores envolvidos foi que, à época da realização da pesquisa, o município de São Gonçalo apresentava uma série de problemas na área de segurança pública, com notável destaque para os casos de violência doméstica, especialmente os relativos a vítimas do sexo feminino. Nesse sentido, tendo por base o contexto de consecução do Diagnóstico Municipal de Segurança Pública de São Gonçalo, Barbosa et al. (2008) apontam que

\footnotetext{
12 Os dados apresentados nessa etapa da pesquisa foram construídos com base nos indicadores disponibilizados por distintas agências públicas, dentre as quais pode-se mencionar: IBGE - Instituto Brasileiro de Geografia e Estatística - Censo (2000); Fundação CIDE - Anuário Estatístico (2006); Pesquisa Nacional de Saneamento Básico (2005); CNES - Cadastro Nacional de Estabelecimentos de Saúde; DATASUS Banco de Dados do Sistema Único de Saúde; SINAN - Sistema de Informação de Agravos em Notificação; ISP - Instituto de Segurança Pública (Secretaria de Segurança Pública do Estado do Rio de Janeiro).

13 Durante o período de realização da pesquisa, foram mapeadas e analisadas as notícias veiculadas em dois jornais diários que se ocupam regularmente do cotidiano do município em tela, a saber: O São Gonçalo e O Fluminense.
} 
De acordo com dados do Instituto de Segurança Pública (ISP) do Rio de Janeiro referentes a 2006 e o primeiro semestre de 2007, o município figura entre os primeiros lugares no ranking estadual dos crimes cometidos contra a mulher, sendo que apenas os casos de ameaça registrados totalizaram 2.657 ocorrências no ano de 2006, levando São Gonçalo à segunda posição no ranking estadual, e 1.617 ocorrências no ano de 2007, o que manteve o município na segunda colocação em relação a essa modalidade específica de crime. Quanto aos casos de estupro, foram registradas 84 ocorrências no ano de 2006 e 37 no ano de 2007, o que colocou o município, respectivamente, em terceiro e quarto lugares no ranking estadual. Já os registros de atentado violento ao pudor totalizaram, consecutivamente, 56 e 39 ocorrências nos anos de 2006 e 2007, elevando São Gonçalo à sétima e terceira posições no ranking estadual, respectivamente, enquanto os crimes de lesão corporal registrados totalizaram 2.529 ocorrências no ano de 2006, pondo, assim, o município na segunda posição no ranking estadual, e 1.430 ocorrências no ano de 2007, o que o erigiu à terceira colocação, no referido período. Por fim, quanto aos casos de homicídio doloso, foram registradas 23 ocorrências no ano de 2006 e 11 no ano de 2007, colocando São Gonçalo, respectivamente, em quarto e oitavo lugares, respectivamente, no ranking estadual (p. 397).

Apesar disso, isto é, a despeito do destaque quantitativo conferido aos casos de ameaça, lesão corporal dolosa, atentado violento ao pudor e estupro, tais cursos de ação - em que a proximidade relacional e a convivência territorial figuram como componentes notoriamente fundamentais - não costumavam receber o mesmo destaque nas manchetes de jornal ou nos discursos dos entrevistados, quando estes eram provocados a discorrer sobre os problemas que consideravam mais graves na área de segurança pública, em âmbito municipal.

Ainda que alguns deles (via de regra, policiais) fossem incisivos ao afirmar que, em São Gonçalo, não havia disputas de territórios por facções rivais do tráfico ou mesmo que os traficantes não dispunham de grande poderio armado, eram as questões ligadas à propalada violência derivada do tráfico varejista de drogas ilícitas que costumavam ocupar posição de centralidade no discurso da maioria dos interlocutores da pesquisa. Assim, embora aquilo a que os entrevistados chamavam de violência não raro se constituísse num objeto difuso - alvo, portanto, de difícil caracterização -, o mesmo não se da- 
va com o sujeito social tido como responsável por sua objetivação. Representado, não só nos textos jornalísticos como nas entrevistas, como o grande algoz dos gonçalenses, o tráfico foi apontado, durante a realização da pesquisa, por ao menos nove em cada dez entrevistados, como o ator coletivo mais diretamente responsável pelos problemas na área de segurança pública no município de São Gonçalo.

\section{VIOLÊNCIA(S), VISIBILIDADE SOCIAL E GRUPOS DE INTERESSE: O PAPEL DA MÍDIA NO AGENDAMENTO DE POLÍTICAS PÚBLICAS BRASILEIRAS}

Pode-se afirmar que se, a exemplo de outros países, no Brasil também ocorreu a criminalização da violência doméstica, isso não significa que, entre os brasileiros, tal tipo de ação criminosa tenha assumido o mesmo clamor público ou ocupado posição igualmente destacada nos noticiários. Como já salientado, em cidades brasileiras de médio e grande porte, como o Rio de Janeiro, por exemplo, é a chamada criminalidade urbana violenta que costuma ser o principal foco de atenção da mídia e, consequentemente, do poder público. De acordo com um discurso largamente difundido entre os jornalistas, o privilégio a esse tipo de questão tem a ver com o fato de que, nas últimas décadas, a violência derivada do tráfico teria atingido níveis tão elevados que não há mais como a grande mídia deixar de reconhecer o problema nem, muito menos, lhe conferir espaço.

Dito de outro modo, isso quer dizer que, diante do quadro generalizado de insegurança que acompanha o aumento dos índices de criminalidade no meio urbano, os agentes midiáticos não teriam o que fazer, senão aumentar também o volume de reportagens dedicadas à temática em questão. Assim, em contraposição às alegações de que, atualmente, haveria muito espaço para a violência nos meios de comunicação, vários jornalistas brasileiros tendem a se defender com base no argumento de que não teria sido o espaço conferido ao fenômeno violento que aumentou, mas o fenômeno em si que assu- 
miu dimensões sem precedentes, tornando-se, então, dotado de maior visibilidade social e, por extensão, de maior visibilidade midiática (SILVA, 2010).

Evidentemente, o discurso que afirma existir uma correspondência direta entre o conteúdo empírico do real e sua representação midiática não pode ser entendido senão como uma construção idealizada, a que os jornalistas recorrem para justificar o seu posicionamento diante dos fatos. Posto que se autodefinem como agentes historicamente comprometidos com o interesse público, ou seja, como os olhos através do quais os cidadãos acompanham o que de mais relevante se passa no mundo, tais profissionais não podem se referir à notícia senão como o relato de fatos cuja importância lhes é dada de antemão e não, portanto, como algo produzido, fabricado ou, por assim dizer, construído.

De acordo com essa perspectiva, o aumento do espaço e da visibilidade conferido ao problema da violência advinda do tráfico de drogas estaria relacionado à percepção de sua generalização, de sua desconcentração, o que teria implicado, segundo se afirma, a subtração dos direitos fundamentais de amplos segmentos da população carioca. O ponto de inflexão em relação à temática encontra-se, assim, diretamente articulada à maneira como, nas últimas décadas, a chamada violência passou a ser reconhecida enquanto ameaça e seus efeitos fizeram-se sentir indiscriminadamente (embora não da mesma forma, nem com a mesma intensidade) pelos mais diferentes grupos ou frações de classe.

Como afirmam Berger e Luckmann (2002), "as instituições e os universos simbólicos são legitimados por indivíduos vivos, que têm localizações sociais concretas e interesses sociais concretos" (BERGER; LUCKMANN, 2002, p. 172). Segundo o raciocínio proposto, é em consonância com tal tipo de perspectiva que se deve buscar uma explicação para a reverberação obtida pela temática da violência nas cidades de grande e médio portes brasileiras. Ao que parece, tal reverberação estaria relacionada ao fato de que, agora, o fenômeno violento encontra-se demasiado próximo de espaços tradicionalmente intocados, o que teria concorrido, de forma direta, para a sua recente transformação de problema social em problema público. A esse respeito, como assinala Zart (2011), 
O problema se torna público quando envolve uma quantidade notável de pessoas, que tem uma organização qualitativa, bem articulada para publicizar o problema, colocá-lo na agenda dos fazedores de políticas (policymakers), gerar normas, procedimentos nos espaços estruturados e estruturais do Estado, institucionalizando os problemas, as proposições e as metodologias de participação para gerar respostas adequadas (ZART, 2011, p.13-14).

Se de fato os membros de algumas camadas sociais conseguem mobilizar mais canais de reivindicação que outras, as questões que lhes dizem respeito tendem, consequentemente, a receber maior destaque que as demais, ocorrendo o mesmo com as respostas institucionais que lhes são endereçadas. Destarte, à medida que grandes órgãos de comunicação dedicam-se a veicular reportagens sobre o crime organizado e este passa a ser tratado como de interesse prioritário, a possibilidade de o tema receber alguma atenção das autoridades competentes tende a ser significativamente maior do que o que se passa com aquelas questões que não recebem o mesmo tipo de encaminhamento.

Considerando-se que "uma política pública é uma diretriz elaborada para enfrentar um problema público" (SECCHI, 2010, p. 2), resta reconhecer que, nos últimos tempos, tem sido cada vez mais raro esse tipo de política ser orientado a despeito daquilo que é noticiado nos meios informativos, sobretudo nos de grande circulação. Isso porque, conforme se procurou assinalar, os jornalistas desempenham um importante papel de mobilização da opinião pública, sendo essa uma de suas principais contribuições para lidar com os problemas sociais. A esse respeito, há quem diga, inclusive, que ao lidar desse modo com tais problemas, a mídia não só produz e difunde informação, como desenvolve um papel genuinamente político. Papel este que passa, em primeiro lugar, pela produção da visibilidade pública de determinadas temáticas, uma vez que, sem isso, não há como se estabelecer uma discussão social em torno dos problemas e, consequentemente, obter as tão almejadas respostas institucionais. 


\section{CONSIDERAÇÕES FINAIS}

Como diz Bourdieu (2002, p. 35), "cada sociedade, em cada momento, elabora um corpo de problemas sociais tidos por legítimos, dignos de serem discutidos, públicos, por vezes oficializados e, de certo modo, garantidos pelo Estado". Dadas as transformações relativas à produção e ao fluxo de informações na contemporaneidade, pode-se dizer que a visibilidade dos fenômenos e sua definição como problemas públicos têm sido cada vez mais dependentes do modo como eles são tratados pela mídia. Afinal, é ela quem traz a público as questões sociais tidas como mais relevantes, tornando-as amplamente conhecidas e, por consequência, aptas a frequentar a agenda dos problemas de Estado. De forma objetiva, isso significa dizer que, por meio do cumprimento de um circuito evocativo que tem na mídia um importante elemento de construção social, determinadas temáticas acabam por ser preferencialmente definidas como de "interesse público", ao passo que outras caem no limbo do esquecimento ou são, comparativamente, relegadas a um lugar secundário no plano das representações e demandas coletivas.

Posto que a mídia participa dos processos de evocação, imposição e legitimação das temáticas de "interesse público", tal definição se vê, portanto, inevitavelmente ligada, em maior ou menor grau, às causas abraçadas pelos grandes veículos de comunicação. Daí a inexorável conclusão de que, para além de informar, a mídia opera como um dos mais importantes atores na construção dos problemas públicos. No caso específico da(s) violência(s), participa ativamente de tal processo à medida que denuncia determinadas modalidades de crime, responsabilizando determinados atores ou agentes e os associando à imagem de uma anomalia social a enfrentada.

Assim, não constitui exagero afirmar que, ao produzir e difundir representações sobre determinados fenômenos, os veículos de comunicação atuam num duplo sentido de lhes conferir projeção social e prescrever o modo como devem ser encarados pelo poder público. Mais do que simplesmente promover a circulação de informações, portanto, a mídia concorre para a produção e difusão de determinadas visões da realidade, contribuin- 
do, assim, de forma decisiva, para (re)criar a realidade que, supostamente, pretende descrever. É, precisamente, ao fazer isso que ela desempenha com maior clareza o seu papel político ou, dito de outra forma, que ela participa, de modo efetivo, da transformação de problemas sociais em problemas públicos, tal qual aconteceu, por exemplo, com o caso da violência doméstica em Portugal e com a violência urbana derivada do tráfico varejista de drogas ilícitas, no Brasil.

\section{REFERÊNCIAS}

1. ALVES, Carla Cristina Costa. Nelson Rodrigues e a reportagem policial: realidade x ficção. 94 p. Monografia (Graduação em Comunicação Social), Universidade Estadual do Rio de Janeiro, 2001.

2. BARBOSA, Antônio Rafael; MOUZINHO, Gláucia Maria Pontes; LIMA, Roberto Kant de; SILVA, Edilson Márcio Almeida. Reflexões sobre a municipalização da segurança a partir do diagnóstico de segurança pública do município de São Gonçalo (RJ). Civitas: Revista de Ciências Sociais, v. 8, n. 3, Porto Alegre, p. 386-408, 2008.

3. BERGER, Peter; LUCKMANN, Thomas. A construção social da realidade: tratado de sociologia do conhecimento. 22. ed. Petrópolis: Vozes, 2002.

4. BOURDIEU, Pierre. O poder simbólico. 5. ed. São Paulo: Bertrand Brasil, 2002.

5. CUNHA, Edite da Penha; CUNHA, Eleonora Schettini M. Políticas públicas sociais. In: CARVALHO, Alysson et al. (Org.). Políticas públicas. Belo Horizonte: Editora UFMG, 2002, p.11-25.

6. DA MATTA, Roberto. Carnavais, malandros e heróis: para uma sociologia do dilema brasileiro. 6. ed. Rio de Janeiro: Rocco, 1997.

7. DIÁRIO DE NOTÍCIAS. APAV recebe por ano pedidos de ajuda de mil homens. Edição de 23 de janeiro de 2012.

8. DICIONÁRIO PRIBERAM DA LÍNGUA PORTUGUESA. Disponível em: http:// bit.ly/2RkPUwm. Consultado em: 30 out. 2015.

9. KANT DE LIMA, Roberto. Carnavais, malandros e heróis: o dilema brasileiro do espaço público. In: GOMES, Laura G.; BARBOSA, Lívia; DRUMMOND, José A. O Brasil não é para principiantes: Carnavais, malandros e heróis, 20 anos depois. Rio de Janeiro: Editora da Fundação Getúlio Vargas, 2000, p.105-124. 
10. KANT DE LIMA, Roberto; MISSE, Michel; MIRANDA, Ana Paula M. de. Violência, criminalidade, segurança pública e justiça criminal no Brasil: uma bibliografia. Revista Brasileira de Informação Bibliográfica em Ciências Sociais, Rio de Janeiro: Relume/Dumará, n. 50, p. 45-124, 2000.

11. LIMA, Lana Lage da Gama; SOUZA, Suellen André de. Representações de gênero e atendimento policial a mulheres vítimas de violência. Revista Internacional Interdisciplinar - INTERthesis. Florianópolis, v. 6, n. 2, p. 61-85, 2010.

12. MARCONDES FILHO, Ciro. O capital da notícia: jornalismo como produção social de segunda natureza. São Paulo: Ática, 1986.

13. MISSE, Michel. Sobre a acumulação social da violência no Rio de Janeiro. Civitas: Revista de Ciências Sociais, Porto Alegre, v. 8, n. 3, p. 371-385, 2008.

14. SECCHI, Leonardo. Políticas públicas: conceitos, esquemas de análise, casos práticos. São Paulo: Cengage Learning, 2010.

15. SILVA, Edilson Márcio Almeida da. Notícias da violência urbana: um estudo antropológico. Niterói, RJ: EDUFF, 2010.

16. THOMPSON, John B. A mídia e a modernidade: uma teoria social da mídia. 4a ed. Petrópolis, RJ: Vozes, 2002.

17. ZART, Laudemir Luiz. Políticas públicas. Educação do Campo: formação e desenvolvimento comunitário (Série Sociedade Solidária, Caderno Pedagógico I, v. I, n. 1). Cáceres/MT: Editora Unemat, p.13-15, 2011. 